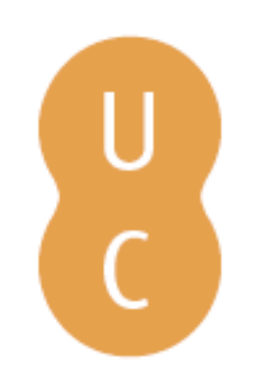

\title{
pompalina
}

\section{Teoria da classificação e focumentos fotográficos em Arquivos, Bibliotecas e Museus}

\author{
Autor(es): $\quad$ Albuquerque, Ana Cristina \\ Publicado por: Imprensa da Universidade de Coimbra \\ URL \\ persistente: URI:http://hdl.handle.net/10316.2/31892 \\ DOI: $\quad$ DOI:http://dx.doi.org/10.14195/978-989-26-0319-3_18 \\ Accessed : $\quad$ 26-Apr-2023 08:32:44
}

A navegação consulta e descarregamento dos títulos inseridos nas Bibliotecas Digitais UC Digitalis, UC Pombalina e UC Impactum, pressupõem a aceitação plena e sem reservas dos Termos e Condições de Uso destas Bibliotecas Digitais, disponíveis em https://digitalis.uc.pt/pt-pt/termos.

Conforme exposto nos referidos Termos e Condições de Uso, o descarregamento de títulos de acesso restrito requer uma licença válida de autorização devendo o utilizador aceder ao(s) documento(s) a partir de um endereço de IP da instituição detentora da supramencionada licença.

Ao utilizador é apenas permitido o descarregamento para uso pessoal, pelo que o emprego do(s) título(s) descarregado(s) para outro fim, designadamente comercial, carece de autorização do respetivo autor ou editor da obra.

Na medida em que todas as obras da UC Digitalis se encontram protegidas pelo Código do Direito de Autor e Direitos Conexos e demais legislação aplicável, toda a cópia, parcial ou total, deste documento, nos casos em que é legalmente admitida, deverá conter ou fazer-se acompanhar por este aviso.

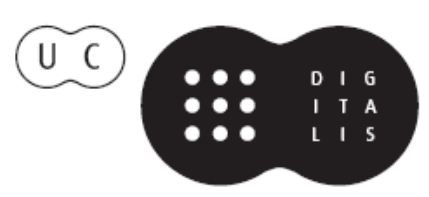


Maria Manuel Borges

Elias Sanz Casado

Coordenação

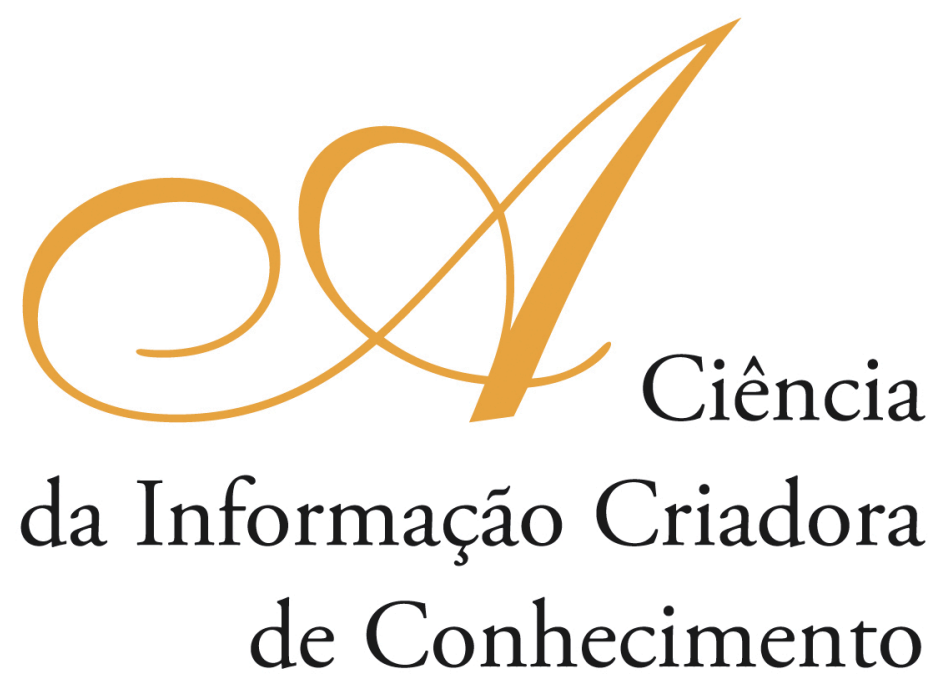

Vol. I

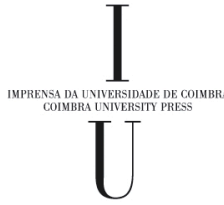

- COIMBRA 2009 


\title{
Teoria da classificação e focumentos fotográficos em Arquivos, Bibliotecas e Museus.
}

\author{
Ana Cristina Albuquerque \\ Universidade Federal do Mato Grosso (Brasil)
}

\section{Resumo}

Iniciamos como projeto investigativo um estudo conceitual do termo classificação, partindo da problemática que, apesar do número significativo de trabalhos e discussóes apresentadas à área da Ciência da Informaçáo sobre o tratamento do documento fotográfico em unidades de informação, este ainda enfrenta desafios pelos profissionais que atuam junto a bibliotecas, arquivos e museus e questionamentos que, se devidamente levantados, poderão contribuir para melhorar e elucidar dúvidas tanto como estabelecer um maior aprofundamento na questão técnica e intelectual desse documento. Para tanto, propomos um estudo teórico e conceitual da Teoria da Classificação, desde seu sentido filosófico até as classificações bibliográficas a fim de analisar como é feita a classificação de documentos fotográficos no acervo do arquivo, museu e biblioteca escolhidos para a pesquisa e constatar a eficácia e importância da prática da classificação, atividade considerada como uma das mais importantes pelos profissionais ligados à Ciência da Informação, no tratamento de um acervo.

\section{Introdução}

O documento fotográfico está presente em diversas áreas do conhecimento e em algumas se torna um elemento quase que indispensável para pesquisas, sendo usado para observaçóes de culturas e povos juntamente a diários de campo pela antropologia; para diagnosticar doenças com fotografias científicas no caso da medicina; verificar as mudanças numa cidade, suas construçóes e urbanização na arquitetura; como objetos de valor histórico pela sociologia e historiografia. Estes são apenas alguns exemplos da importância do documento fotográfico para, junto a textos escritos, demonstrar fatos do presente ou do passado.

Embora se tratando apenas de uma representação do real, a fotografia adquiriu verdadeira credibilidade quanto a suas imagens e, graças aos registros constantes e experiências fotográficas, grande parte do que conhecemos hoje de pequenos e breves momentos passados - cidades, povos, ou seja, tudo o que foi registrado a partir do aparecimento da fotografia - são, além de recordaçóes, documentos históricos que nos mostram, aliados a outras formas de expressão, importantes momentos que devem ser conhecidos para a construção de uma determinada memória.

A fotografia, desde seu aparecimento, foi vista através de seu caráter documental, baseado no princípio de prova e realidade que a caracterizam. Talvez por esse motivo, sua capacidade de representar cenas como se fossem totalmente reais, exerça um fascínio que se junta à vontade de guardar, tanto no sentido afetivo quanto documental. 
Assim, vão se formando coleções de fotografias. A organização e classificação dadas a estas coleçóes refletem o pensamento de uma época. De acordo com Pavão apud Gonçalves e Marcondes (2005, p. 263):

[...] não é qualquer agrupamento ou conjunto de fotografias que se pode considerar uma coleção de fotografias. À noção de coleção preside um intuito, que lhe confere uma unidade, um significado próprio, difícil de encontrar num aglomerado de fotografias. Cada elemento que integra uma coleção faz parte de um todo, ganha sentido individual e coletivo precisamente através do conjunto. É a esta noção de um todo orgânico que podemos chamar coleção.

A questáo a que se refere o autor nos remete à teoria arquivística do respeito aos fundos ${ }^{1}$, ou seja, as formas de organizar e classificar documentos particulares devem ser mantidas e respeitadas pelas instituiçóes que a recolhem, a fim de "não apagar os traços da sua organicidade, traduzida no modo como ela foi acumulada, reunida e, ainda, naquilo que foi intercambiável nessa reunião" (GONÇALVES;MARCONDES, 2005, p. 263). Tarefa difícil e que exige um trabalho de pesquisa dos profissionais envolvidos no processo de tratamento náo só de arquivos como de todas as instituições que possuem acervos fotográficos, pois, "quanto mais uma classificação se adaptar a uma determinada época, menos adequada será para outra” (VICKERY, 1980, p. 187).

Sendo assim, iniciamos como projeto investigativo um estudo conceitual do termo classificação, partindo da problemática que, apesar do número significativo de trabalhos e discussóes apresentadas à área da Ciência da Informação sobre o tratamento do documento fotográfico em unidades de informação, este ainda enfrenta desafios pelos profissionais que atuam junto a bibliotecas, arquivos e museus e questionamentos que, se devidamente levantados, poderão contribuir para melhorar e elucidar dúvidas tanto como estabelecer um maior aprofundamento na questáo técnica e intelectual desse documento.

Outro problema observado, no caso específico do assunto classificação de documentos fotográficos, é a escassa bibliografia acadêmica das áreas da museologia, biblioteconomia e arquivologia, que não contemplam discussóes nem tratam profundamente este tema. Temos, de maneira mais trabalhada, a questão da indexação de fotografias, no entanto quando passamos para os arquivos por exemplo, percebemos que a classificação ainda é tema de muito debate entre os profissionais da área, portanto, esta proposta visa sistematizar como a classificação se dá nas três áreas para depois discutir especificamente o documento fotográficos e suas possibilidades de organizaçáo e recuperação da informação.

Desta forma, adentramos no campo dos estudos teóricos e conceituais em relação à classificação do conhecimento e de sua evolução, utilizando o documento fotográfico - modelo de novo suporte informacional - como fator principal para tecermos uma

\footnotetext{
1 "Um documento de arquivo só tem sentido se relacionado ao meio que o produziu. Seu conjunto tem que retratar a infra-estrutura e as funçóes do órgão gerador. Reflete, em outras palavras, suas atividades-meio e suas atividades-fim. Esta é a base da teoria de fundos.” (BELLOTTO, 1991, p.8-9).
} 
discussão sobre a importância, estado atual e contribuiçôes epistemológicas sobre a classificação de documentos fotográficos nas áreas da Teoria da Classificação, Ciência da Informaçáo, Biblioteconomia, Arquivologia e Museologia.

\section{Classificação e algumas definiçôes}

Partindo da Grécia Antiga, ou até mesmo antes, em sociedades primitivas, a intenção de colecionar objetos se faz presente. Acumular e guardar tesouros para oferecer ao olhar, mesmo que sua função útil seja uma questão que fique em segundo plano, é uma prática que atravessa séculos.

Possuir e preservar aquilo que se deseja, que se valoriza e se acredita que não deve ser esquecido descobre sentido no ato de colecionar (MARQUES;SILVEIRA, 2005) e, com o ato de selecionar objetos, estabelece-se também um significado em relação a eles. Esses objetos, coletados e diferenciados trazem a possibilidade de formar uma classificação das coisas, que, por sua vez, deve ser explicada e entendida de acordo com seu contexto histórico. Encontram-se coleçóes famosas como a de Alexandria ${ }^{2}$, que indicou para os estudiosos como uma instituição pode proteger a memória tendo num mesmo espaço uma biblioteca, um arquivo e um museu com coleçóes de plantas, animais e artefatos da natureza.

No entanto, não são apenas as coleçôes materiais que emergem para o reconhecimento de diferentes objetos que permeiam o mundo em que vivemos. Para entender esse mundo, o homem colecionou também "os modos de conhecimento e as cosmologias que elaborava na forma de mitos” (MENEGAT, 2005, p.05.). Lévi-Strass diz que colecionando fatos e narrativas e passando adiante o homem constrói um determinado modo de pensar o mundo, assim como as coisas que o constituem. Lévi-Straus, em "O pensamento selvagem":

[...] alerta que isso constitui o substrato da própria ciência, ou seja, a ciência moderna não poderia surgir repentinamente nos séculos XVI e XVII já plena de paradigmas revolucionários. Foi necessária, antes, uma longa caminhada de coleta, seleção de materiais e tentativas de explicar e entender o mundo que está antes do pensamento clássico e remonta à própria origem daquilo que chamamos humano. Como diz Lévi-Strauss, toda classificação é melhor que o caos". (MENEGAT, 2005, p. 06).

Colecionar o mundo, através de objetos materiais ou não, é representá-lo incidindo valores e sentidos. Dentro desse ato, o homem tentou dar desde sempre às suas coleçóes uma ordem para representar seu pensamento ou desejo, o que contribuiu para o desenvolvimento e determinação de classificaçóes do conhecimento.

De acordo com Pomian (2004, p.53), uma coleção é:

\footnotetext{
2 "os atuais museus devem o seu nome aos antigos templos das Musas. Todavia, o mais famoso de entre estes, o Museu de Alexandria, não o era por causa das colecçóes de objetos; tornou-se famoso graças à sua biblioteca e à equipe de sábios que aí viviam em comunidade”. (POMIAN, 2004, p.56).
} 
qualquer conjunto de objetos naturais ou artificiais, mantidos temporária ou definitivamente fora do circuito das actividades econômicas, sujeitos a uma protecção especial num local fechado preparado para esse fim, e expostos ao olhar do público.

O autor chama a atenção para as condiçôes que, logicamente um conjunto de objetos tem de apresentar para ser considerado uma coleção, sendo que tais condiçóes (acumulação de objetos, tesouros escondidos, coleçóes formadas ao acaso), podem ser satisfeitas por museus, bibliotecas e arquivos, respeitando, em cada uma, sua organização, origem e a função que é dada aos documentos.

Essas instituiçôes que começaram juntas em seus acervos têm características que são comuns até hoje como o fato de preservar a memória coletiva, atividade que envolve muito mais do que apenas manter e proteger essa memória. Museus, bibliotecas e arquivos, têm como função primordial expor seus acervos, atender seus usuários de forma a recuperar informaçôes, oferecer material à pesquisas e lazer.

Todo esse trabalho se define na organização e tratamento de seus acervos. Coletar, organizar, identificar, catalogar e classificar qualquer tipo de suporte são atividades que norteiam a montagem de um acervo e fazem dessas instituições lugares onde ficam depositadas coleçóes que fazem parte da história de diferentes culturas.

Percebe-se, nesse caso, que o tratamento de acervos nasce juntamente com o desenvolvimento das ciências e com a necessidade de dar a uma determinada coleção, dentro de um ambiente próprio, o acesso às suas informaçôes. As atividades que são executadas nessas instituiçôes vêm da capacidade de colecionar e estão ligadas a todo desenvolvimento das classificaçóes do conhecimento, dos seres e dos saberes, ou seja, antes das práticas legitimadas pelas instituições está a coleção (LARA FILHO, 2006).

E, em cada uma das coleçóes armazenadas por uma instituição para compor seu acervo, há a forma como foi organizada e classificada ao longo de sua história, mantendo uma relação tanto com seu dono como com sua época. Nesse sentido Vickery (1980), escreve baseado na opiniáo de teóricos como Lund e Taube que os sistemas de classificação não podem ser permanentes, com formas e sentidos definidos porque a História:

[...] apresenta uma série de épocas culturais. Cada uma corresponde a um curto período de anos nos quais o conhecimento apresenta uma estrutura mais ou menos unificada que pode ser expressa numa classificação, mas cada nova época exige uma nova classificação. (VICKERY, 1980, p. 187).

Portanto, inicialmente para contextualizar nosso estudo, procuraremos definir o termo classificação em seu sentido filosófico e social, para, a seguir adentrarmos em seu aspecto especializado, as classificaçôes bibliográficas e teoria da classificação, em bibliotecas, arquivos e museus.

O termo classificação se caracteriza pelo processo de agrupar e dividir o conhecimento por suas semelhanças, dispor as informaçóes de modo que suas relaçóes de analogia se sobressaiam, para que as ciências, o saber ou documentos possam ser apreendidos de forma precisa. "Classificar, na acepção mais simples do termo, é reunir coisas ou idéias 
que sejam semelhantes entre si, e separar as que apresentam diferenças" (VICKERY, 1980 , p. 23). Através da classificação é possível escolher dentro de diversas entidades - que de acordo com Vickery (1980) são seres concretos e conceituais - as características que melhor têm relação com a entidade que foi determinada anteriormente.

Na perspectiva de Peńa (2003, p.30):

Es el acto de organizar el universo del conocimiento en algún orden sistemático. Ha sido considerada la actividad más fundamental de la mente humana. El acto de clasificar consiste en el dicotómico proceso de distinguir cosas u objetos que poseen cierta característica de aquellos que no la tienen, y agrupar en una clase cosas u objetos que tienen la propiedad o característica en común.

Reunir em classes um maior ou menor número de afinidades entre as diversas realidades a classificar faz do ponto de vista do homem "o único princípio a partir do qual a classificação pode se estabelecer” (POMBO, 2002, p. 09).

Antes de tudo a classificação é instintiva, mesmo sendo uma atividade intelectual. Se tratada do ponto de vista antropológico, veremos em exemplos, como o já citado Lévi-Strauss ${ }^{3}$ e Durkheim (1969), estudos que enfatizam compreender as características e o modo de classificaçóes sociais em diferentes culturas, pois, se torna importante contextualizá-la como um fenômeno social, que é parte constitutiva da sociedade, na medida em que náo se pode deixar de percebê-la em toda parte. Segundo Burke (2003, p.78)

De Durkheim em diante os antropólogos desenvolveram uma tradição de levar a sério as categorias ou classificaçóes das outras pessoas, investigando seus contextos sociais. A tradição inclui estudos clássicos como O pensamento chinês (1934), de Marcel Granet, por exemplo, apresentou as categorias chinesas yin e yang como exemplos de pensamento concreto ou pré-lógico. Lévi-Strauss rejeitou a idéia de pré-lógico, mas também ele destacou as categorias concretas dos chamados povos primitivos, como os índios americanos, que fazem uma distinção análoga ao nosso contraste entre "natureza" e "cultura" com as categorias do "cru" e do "cozido".

Classificamos de forma natural, reconhecendo desde crianças relaçóes de semelhança, em estágios que Piaget (GIL, 2001, p.94), define em três: para uma criança é possível perceber passo a passo o universo cheio de imagens e objetos onde vive, construindo suas "coleçôes figurais" que, com o tempo deixam de ser "apenas figurais e obtém-se gradualmente a distinção entre "alguns" e "todos", isto é, a noção de classe" (GIL, 2001, p. 95), que gera, por fim a noção de hierarquia, ou seja, mesmo que não conheça as noções científicas e matemáticas de uma classificação, os seres humanos desde sempre tendem a constituir e agrupar formas, executando assim a função de categorizar.

A relação que se instituiu com as coisas e com o mundo, fez com que a classificação se tornasse importante para determinar uma ordem na ciência. As classificaçóes:

\footnotetext{
3 Ver Lévi-Strauss, Le totémisme aujourd'hui, (1962).
} 
[...] constituem os pontos estáveis que nos impedem de rodopiar sem solo, perdidos no inconforto do inominável, da ausência de "idades" ou "geografias". Só elas nos permitem orientar-nos no mundo à nossa volta, estabelecer hábitos, semelhanças e diferenças, reconhecer os lugares, os espaços, os seres, os acontecimentos; ordenálos, agrupá-los, aproximá-los uns dos outros, mantê-los em conjunto ou afastá-los irremediavelmente. (POMBO, 2002, p. 01).

Segundo Araújo (2006, p.177), a definição do termo em questão pode "variar um pouco", no entanto:

[...] traz o elemento essencial que caracteriza um processo de classificação: a formação metódica e sistemática de grupos, a ação organizante de ordenar um determinado conjunto de seres ou coisas em agrupamentos menores, a partir de características semelhantes partilhadas por alguns (que os incluem dentro de determinado grupo) e não compartilhada pelos demais (que não pertencem a esse grupo). Nesse processo elege-se um critério de divisão, promovem-se definiçóes e aproximações, estatutos e avaliaçóes.

Com as classificações, tem-se a pretensão de organizar o universo do conhecimento em uma ordem sistemática, pois agrupa não só o conhecimento, mas também objetos em uma classe comum.

Aristóteles teve grande contribuição na organização intelectual do conhecimento. Por quase dois mil anos o que se conhecia e se utilizava de classificaçáo do conhecimento vem principalmente do modelo que estabeleceu que, de acordo com Vickery (1980), permaneceu com a estrutura básica até quase o fim do século XVII. Burke (2003, p. 90) escreve que:

Aristóteles expusera um sistema de 10 categorias gerais (substância, quantidade, qualidade, relação, lugar, tempo, posição, condição, ação e paixão). Essas categorias eram largamente conhecidas e utilizadas (de fato ainda as utilizamos hoje, mesmo que não mais a consideremos um sistema fechado).

Enquanto as categorias, através da linguagem, definem a noção de realidade, as classificaçôes agrupam e dividem o conhecimento, utilizando classes hierárquicas e critérios oportunamente escolhidos. Gil (2001, p.91) esclarece que em relação às categorias, as classificaçóes:

[...] por outro lado, são uma manifestação directa do pensamento categorial. No sentido mais preciso, as noçóes de entidade, de qualidade, de relação e de quantidade intervém de modo imediato nas classificaçóes - classificam-se populaçóes de objetos, segundo as suas propriedades e as suas interaçóes com outros objetos. As classificações representam uma actualização não menos directa do par identidade/ diferença, do mesmo e do outro, e estabelecem-se sobre uma relaçáo de precedência (de cada nível relativamente ao seguinte) isto é, sobre uma modalidade do par anterior/posterior [...]. 
No entanto, à medida que se tem a percepção análoga dos fatos e objetos, também se trabalha com suas diferenças. Já nos “Tópicos de Aristóteles” as semelhanças e contrastes erigem no mecanismo principal para a organização de quaisquer formas (GIL, 2001, p.52). É um lidar constante com escolhas. O que fica é, no entender do classificador, o que realmente representa o elemento classificado, e a escolha se dá descartando informaçôes. Optar por uma ou outra propriedade fará com que diferentes arranjos da realidade constituam diferentes tipos de classificaçóes, como explica Diderot apud Pombo (2002, p. 08):

Quer o universo seja real ou inteligível, há uma infinidade de pontos de vista sob os quais pode ser representado e o número dos sistemas possíveis do conhecimento humano é tão grande como o desses pontos de vista.

A classificação se estabeleceu com a fundamentação de teorias filosóficas e científicas que deram base ao seu desenvolvimento. As categorias ${ }^{4}$, exemplos realistas de descrição de qualquer experiência, são um primeiro estágio para que a classificação das ciências e do saber se desenvolva e se concretize ${ }^{5}$.

Baseada em semelhanças e contrastes, pode reunir a síntese e a análise, pois é "o meio mais simples de, simultaneamente, discriminar os elementos de um conjunto e agrupá-los em subconjuntos - isto é, de analisar e sintetizá-lo" (BUNGE apud GIL, 2001. p. 91). Dessa forma, percebe-se também a relação com o desenvolvimento do conhecimento, pois, com a organização deste em classes, sua função se estende à de unificar e sistematizar os fatos e dados, com espaços que permitem crescer a partir do exterior, ou seja, nível a nível de acordo com a hierarquia.

A comparação de dois objetos implica em um dado comum a eles, dessa forma podese analisar o que se tem de igual e de diferente e estabelecer uma sucessão de graus, ou seja, séries. Essas séries levam à presença da ordem e assim chega-se a diferentes graus de complexidade. A ordem do mundo começa a se desvincular dos exemplos totalmente materiais e passa a se revelar no saber. Para isso Foucault (1986) escreve que é necessária a linguagem, pois esta pode representar todas as representaçóes e tornar-se universal, expressar todo o mundo, representá-lo, ou tornar-se uma enciclopédia, que se faz real com Diderot e D'Alembert. A ordem das enciclopédias, que tem a função de selecionar e sintetizar as informaçóes, e dos currículos das universidades influi diretamente na

\footnotetext{
4 “Em geral, qualquer noção que sirva como regra para investigação ou para sua expressão lingüística em qualquer campo. Historicamente o primeiro significado atribuído às categorias é realista: elas sáo consideradas determinaçóes da realidade e, em segundo lugar, noçóes que servem para indagar e para compreender a própria realidade. Foi essa a concepção de Platão, que as chamou de gêneros supremos e enumerou cindo desses gêneros”. (ABBAGNANO, 2000, p.121).

5 "O ponto de partida tradicional para se construir uma classificação tem sido o "universo" do conhecimento, que se divide em classes convencionais principais. As "entidades" (seres concretos e conceituais) em cada classe principal têm muitos atributos, e alguns deles podem servir como características para a "divisão lógica" da classe principal em subclasses ou grupos. Os grupos assim derivados podem ser depois dispostos numa ordem útil. Cada grupo é em si um "universo" puro suscetível de divisão por uma outra característica. A divisão sucessiva por uma série de características resulta numa cadeia de classes." (VICHERY, 1980, p. 234).
} 
ordem dos livros em uma biblioteca ou de coleçôes em museus. Nos séculos XVII e XVIII, uma reclassificação do saber por conta das universidades fazia com que todo o mecanismo do conhecimento também se reorganizasse, refletindo a conjuntura nas instituiçôes ligadas ao saber (BURKE, 2003). De acordo com o autor:

Nas bibliotecas também houve uma reclassificação, em parte como resultado de mudanças na organização das universidades, mas também como resultado da multiplicação de livros que se seguiu à invenção da imprensa, um fluxo que chegou a alarmar estudiosos. (BURKE, 2003, p. 97).

Esse fluxo fez com que filósofos e estudiosos pensassem em um sistema de classificação para que os livros fossem encontrados e organizados da melhor maneira. As decisões pragmáticas que tinham de ser tomadas na organização de bibliotecas implicava na técnica e na sabedoria dos estudiosos, "seriam necessários filósofosbibliotecários ou bibliotecários-filósofos, combinando os talentos de John Dewey, o filósofo pragmático, com os de Melvil Dewey, criador do famoso sistema decimal de classificação" (BURKE, 2003, p.98).

O fato é que nos séculos XVII e XVIII aconteceram muitas mudanças na concepção do que era o conhecimento. Este passou de seu caráter teórico para se tornar útil, o que foi novidade na época. Isso se reflete na organização das unidades que armazenavam o conhecimento, bibliotecas, arquivos e museus, que, pela primeira vez se vêem norteados por uma especificidade funcional, desvinculando-se da classificação dos saberes. Essa quebra da teoria para a prática vai alavancar um grande interesse e a criação de uma "ciência da classificação", surgindo, as classificaçôes bibliográficas, estas baseadas nas classificaçóes filosóficas, a partir do século XIX (LARA FILHO, 2006). Segundo Pombo (2002, p.03):

O objecto de análise é então o conceito de classificação na sua idealidade e abstracção máxima; o objectivo, a constituição de uma teoria da classificação que estude a totalidade dos possíveis sistemas de classificação e determine os meios da sua realização. Domínio que, interessando directamente aos classificacionistas, solicita de novo a colaboraçáo dos filósofos.

A classificação passa a ter uma nova função: a de organizar no sentido prático, e se divide das classificações filosóficas. Svenonius apud Araújo (2006), propóe uma separação entre as classificações dos filósofos, enciclopedistas e epistemólogos, que são mais voltados à classificaçáo do conhecimento, da preocupação com a organização de documentos, assim como sua disposição física e recuperação.

Barbosa (1969) define também uma classificação filosófica, que trata das questôes dos conhecimentos humanos, sendo muito teóricas e as classificaçóes bibliográficas, que também se preocupam com a questão do conhecimento, mas se centram em dar um "lugar determinado aos livros nas estantes" (BARBOSA, 1969, p. 47).

Piedade (1983, p. 60) também se refere a essa divisão:

Segundo a finalidade a que se destinam podem ser: sistemas de classificação filosóficos ou sistemas de classificação bibliográficos. As classificações filosóficas são 
as criadas pelos filósofos, com a finalidade de definir, esquematizar e hierarquizar o conhecimento, preocupados com a ordem da ciência ou a ordem das coisas. As classificaçôes bibliográficas são sistemas destinados a servir de base à organização de documentos nas estantes, em catálogos, em bibliografias etc.

Além das definiçóes dos autores, existem muitas formas de distinguir os diversos modos de classificação bibliográfica, mas, apesar de todas as diferenças identificadas, o que se pode perceber é que "todas as teorias da classificação bibliográfica buscam promover uma classificação sistemática, lógica, que reflita crítica e filosoficamente sobre os elementos de ligação que servem para a reunião de conceitos."(ARAÚJO, 2006, p.122).

O estudo do termo e da prática classificatória encontra reduto e discussões consistentes dentro do campo da biblioteconomia, mas também no tocante à museologia e arquivologia encontramos, mesmo que em menor proporção, discussóes a respeito.

Na museologia, Otlet (LARA FILHO, 2006) identifica muitas semelhanças entre uma biblioteca e um museu, que se caracterizam por seus acervos e práticas e defende uma classificação das peças seguindo critérios diversos como cronológicos, geográficos ou outros, que vão depender das características e propósitos que tem o museu.

Já na arquivologia encontram-se discussôes a respeito das classificaçôes em autores como Heredia Herrera (1991), Schellenberg (2004) e Duchein (1969). No entanto, uma teoria da classificação em arquivística, como indica Sousa (2006, p.122), demorou para ser instituída. Segundo o autor: "O reconhecimento da importância dos princípios fundamentais da classificação dos arquivos nem sempre se consolidou em uma prática".

As influências dos grandes sistemas de classificação científica, como nas bibliotecas, também ocorreram nos arquivos, que consideravam o documento apenas através de seu valor informativo, sem considerar o órgão gerador. A partir do século XIX, a teoria de respeito aos fundos foi instituída, mudando assim a organização e princípios da classificação arquivística.

\section{Sobre o documento fotográfico}

Diante desse panorama do surgimento das classificações, podemos nos questionar como é tratada hoje e qual o seu estado atual.

A classificação nas unidades de informação, como escreveu Vichery (1980), mudou de acordo com sua época? Foram abertas discussóes para novos suportes informacionais como a fotografia? Adaptaram-se ou criaram-se novas regras? Esses são alguns dos questionamentos da presente pesquisa em relação à teoria da classificação em bibliotecas, arquivos e museus e mais especificamente no tratamento de coleçôes e acervos de documentos fotográficos.

Esses documentos, por conta da abertura para novas fontes e suportes informacionais com o trabalho da Escola dos Annales, que demonstrou a necessidade de pesquisadores aderirem a diversos tipos de objetos, foram incluídos no bojo de novo suporte e 
documento que contém informaçóes relevantes e que devem ser tratados de acordo com suas particularidades.

Nesse sentido, o novo suporte traz para as instituiçóes como museus, arquivos e bibliotecas não só as coleções fotográficas documentais, as que vão provar algo ou atestar fatos, mas também as que vão reproduzir obras de arte, construçôes arquitetônicas, álbuns de família, permitindo assim transcender os limites da representação e dar uma nova percepção aos objetos que podem ser armazenados por unidades de informação (GROSSMANN, 2005).

O trabalho com documentos fotográficos suscita dúvidas e adaptaçôes que exigem dos profissionais empenho e uma busca pelo melhor caminho a seguir. A "transcodificação" da fotografia (Smit, 1987), ou seja, a passagem de uma linguagem para outra, exige a verbalizaçáo do documento fotográfico, assim, damos início ao tratamento desta para que tenha um sentido, para que seja traduzida e, dentro de uma unidade informacional, possa ser útil com suas informaçóes aos usuários. A imagem fotográfica informa e comunica como qualquer outro documento, mas tem de ser contextualizada e utilizada com um objetivo para que possa oferecer o máximo de seus sentidos.

O documento fotográfico, em uma unidade de informação, através do processo técnico e podemos nos arriscar a falar da aplicação de uma leitura de seus elementos, torna-se visível de forma verbal, diferente da visibilidade em sua forma original, e é essa troca de linguagem que tentamos entender no âmbito de sua classificação e técnicas que permitem ao documento passar posteriormente às fases que completam seu tratamento. De acordo com Mendes (2004, p. 14):

A organização documental e as estratégias de interpretação e classificação permitem antever como diversos segmentos sociais delineiam olhares das histórias do futuro. Nesse quadro são açóes decisivas as formas pelas quais se disponibiliza o acesso a certos conjuntos documentais ou as prioridades dadas para tratamento e pesquisa.

Todas as normas vigentes em bibliotecas, arquivos e museus podem englobar objetos tão singulares como os documentos fotográficos e, estas três instituiçóes têm semelhanças entre si. $\mathrm{Na}$ presente pesquisa procuraremos enfatizar a existência de princípios próprios, específicos a cada área, devido à função da instituição, sua relação com a sociedade e com o suporte informacional, mas também os princípios onde as três se aproximam.

Desse modo, a informação sofrerá uma intervenção diferente em cada tipo de instituição, por parte do profissional específico, para que possa ser acessada pelo usuário. Cada tipo de acervo traz consigo problemas genéricos ao campo, e específicos a cada uma das três áreas a que se filia. E é nesse contexto que está inserida a problemática da classificação em relação ao documento fotográfico e o cerne de nossa pesquisa.

\section{Consideraçóes}

Arquivos, bibliotecas e museus são centros de documentação com grandes semelhanças em sua estrutura funcional. Tendo em vista seus acervos, ambos trabalham com coleções, documentos, catálogos, conservação e classificação. Nas três instituições 
o documento fotográfico se faz presente trazendo suas peculiaridades referentes a seu suporte, origem, função e tratamento que, independente da instituição se aplica aos diversos domínios do saber.

Nesse sentido, a presente pesquisa pretende contribuir com discussões epistemológicas dentro da Ciência da Informação sobre uma das mais relevantes atividades desenvolvidas por unidades de informação: a classificação. Sendo pertinente, pela proposta de sistematizar a conceituaçáo de classificação e a forma como é desenvolvida nas três instituiçôes e, consequentemente, fornecer subsídios teóricos para a compreensão do ato de classificar o documento fotográfico nas diferentes áreas aqui propostas.

A bibliografia quase escassa e poucas reflexóes sobre o tema impulsionam para um maior aprofundamento nas questóes propostas, abrindo caminho para novas reflexóes e contribuiçóes para a atividade considerada de extrema importância para as três áreas.

A fotografia é um meio tecnológico de criação e reprodução de imagens em série. Pelo fato de ser determinada por essas condiçôes materiais de produção, ela desenvolve consequentemente, sua própria linguagem expressiva. Isto é, forma e conteúdo se imbricam de maneira inseparável. Por esses motivos, a fotografia, por um lado, apresenta condições únicas que determinarão seu tratamento em unidades de informação. De maneira que, seja em um arquivo, em uma biblioteca ou em um museu ela sempre apresentará os mesmos traços constitutivos sendo diferentes as funções que serão dadas às suas informaçóes nesses acervos (ALBUQUERQUE, 2006). Dependendo dessa função, sua classificação tem um papel essencial tanto para o profissional quanto para o usuário pesquisador.

\section{Referências bibliográficas}

ALBUQUERQUE, Ana Cristina de. Catalogaçáo e descriçáo de documentos fotográficos: uma aproximaçáo comparativa das normas AACR2 e ISAD (G).

197f. Dissertação (Mestrado). Universidade Estadual Paulista, Faculdade de Filosofia e Ciências, 2006.

ARAÚJO, Carlos Alberto Ávila. Fundamentos teóricos da classificação. In: Encontros Bibli: Revista Eletrônica de Biblioteconomia e Ciência da Informação, Florianópolis, n.22, 2o semestre, 2006. p.117-140.

BARBOSA, Alice Príncipe. Teoria e prática dos sistemas de classificaçáo bibliográfica. Rio de Janeiro: Instituto Brasileiro de Bibliografia e Documentação, 1969.

BELLOTTO, Heloisa Liberalli. Arquivos permanentes: tratamento documental. 2.ed. Rio de Janeiro: Fundação Getúlio Vargas, 2004. 318p.

BURKE, Peter. Uma história social do conhecimento: de Gutenberg a Diderot. Rio de Janeiro: Zahar, 2003.

DURKHEIM, Emile; MAUSS, Marcel. Algumas formas primitivas de classificação. In: De quelques formes primitives de classification. Contribution a l'étude dês representations collectives. Paris: PUF, 1969, p.395-461

FOUCAULT, Michel. A arqueologia do saber. 2.ed. Rio de Janeiro: Forense-Universitária, 1986. 239p. 
GIL, Fernando. Classificaçóes. In: Enciclopédia Einaudi. Portugal: Imprensa Nacional/Casa da Moeda. 2001. 432p. v.41.

GOLÇALVES, Cássia Denise; MARCONDES, Marli. A coleção fotográfica V-8. In: Anais do Museu Paulista: História e Cultura Material, São Paulo, v.13, n.1, p.253-269. jan./jun., 2005

GROSSMANN, Martin. O museu de arte hoje. Fórum permanente: museus de arte entre o público e o privado. Disponível em: <www.forumpermanente.incubadora.fapesp.br/portal/ painel/artigo/o_museu_hoje>. Acesso em 22/05/2007.

HEREDIA HERRERA, Antonia. Archivística general: teoría y práctica. 5. ed. Sevilla: Diputación Provincial de Sevilla, 1991. 510p.

LARA FILHO, Museu: de espelho do mundo a espaço relacional. Dissertação (Mestrado). Programa de Pós-Graduação em Ciência da Informação, Área de Concentração Cultura e Informação. Escola de Comunicação e Artes da Universidade de São Paulo, ECA USP, 2006, 139p.

MENDES, Ricardo. O futuro do presente: acervos fotográficos diante do horizonte digital. In: Anais do Museu Paulista: história e cultura material. São Paulo, v.12, jan./dez., 2004, p. 11-21.

MENEGAT, Rualdo. A epistemologia e o espírito do colecionismo. In: Episteme, Porto Alegre, n.20, p.05-12, jan./jun., 2005.

PENÃ, Catalina Naumis. Indización y clasificación: un problema conceptual y terminológico.

In: Documentación de las Ciencias de la Información, V. 26, 2003, p. 23-40.

PIEDADE, M.A, Requião. Introduçáo à teoria da classificaçáo. 2.ed. Rio de Janeiro: Interciência, 1983. 221 p.

POMBO, Olga. Da classificaçáo dos seres à classificaçáo dos saberes. 2002. Disponível em: <www.educ.fc.ul.pt/hyper/resources/pombo-classififcacao.pdf>. Acesso em 25/05/2007.

POMIAN, Krzysztof. Colecção. In: Enciclopédia Einaudi. Coord. Fernando Gil. Portugal: Imprensa Nacional-Casa da Moeda, 2004. 457p. V.1.

SCHELLENBERG, T.R. Arquivos modernos: princípios e técnicas. 4.ed. Rio de Janeiro: Editora FGV, 2004.386p.

SMIT, Johanna W. A análise da imagem: um primeiro plano. In: Análise documentária: a análise da síntese. 2.ed. Johanna w. Smit (coord.). Brasília: IBICT, 1987. p.101-113.

SOUSA, Renato Tarciso Barbosa. Classificação de documentos arquivísticos: trajetória de um conceito. In: Arquivística Net, Rio de Janeiro, v.2, p.120-142, ago./dez. 2006. Disponível em <aquivisticanet.com.br>. Acesso em 22/05/2007.

VICKERY, Brian C. Classificaçáo e indexaçáo nas ciências. Rio de Janeiro: BNG/Brasilart, 1980. 274p. (Coleção biblioteconomia, documentação, ciência da informação). 